\title{
Effective engagement of survivors of harassment and abuse in sport in athlete safeguarding initiatives: a review and a conceptual framework
}

\author{
Margo Mountjoy (1) , ${ }^{1,2}$ Tine Vertommen, ${ }^{2,3}$ Rachael Denhollander, ${ }^{4}$ Sheldon Kennedy, ${ }^{5}$ \\ Renald Majoor ${ }^{6}$
}

${ }^{1}$ Family Medicine, McMaster University Michael G DeGroote School of Medicine, Waterloo,

Ontario, Canada

${ }^{2}$ International Research Network on Violence and Integrity in Sport, IRNOVIS, Antwerp, Belgium

${ }^{3}$ Medicine and Health Sciences, Universiteit Antwerpen,

Antwerpen, Belgium

${ }^{4}$ rachaeldenhollander.com

Louisville, Kentucky, USA

${ }^{5}$ Respect Group, Calgary,

Alberta, Canada

${ }^{6}$ Breaking the Silence

Foundation, Wehl, The

Netherlands

Correspondence to

Dr Margo Mountjoy, Family Medicine, McMaster University Michael G DeGroote School of Medicine, Waterloo, Canada; mountjm@mcmaster.ca

Accepted 13 December 2021

Check for updates

(c) Author(s) (or their employer(s)) 2022. No commercial re-use. See rights and permissions. Published by BMJ.

To cite: Mountjoy $M$, Vertommen $\mathrm{T}$, Denhollander $\mathrm{R}$ et al. Br J Sports Med 2022:56:232-238.

\section{ABSTRACT}

Sport, as a microcosm of society, is not immune to the abuse of its stakeholders. Attention to abuse in sport has recently become a priority for sport organisations following several high-profile cases of athlete abuse from different sports around the world. Resulting from this increased awareness, many sport organisations have commenced work in the field of athlete safeguarding including the development of policy, educational programmes, reporting pathways, investigation mechanisms and research initiatives. One mechanism adopted by many sport organisations to support their safeguarding efforts is the engagement of survivors of abuse in sport: typically, as guest speakers at conferences or educational events. Unfortunately, many sport organisations do not have the knowledge or trauma-informed expertise to engage survivors safely and effectively; and in doing so, may unintentionally retraumatise the survivor if erroneous methods of engagement are employed. For some survivors, this experience may compound the original harms, and thus it also represents an area of vulnerability for the organising entity. The purpose of this paper is to explore the rationale for partnering with survivors of abuse in sport in safeguarding initiatives and to propose a living conceptual framework to support effective and safe survivor engagement in safeguarding initiatives. We will explore the underpinning scientific background, as well as the 'why', and 'how' of survivor engagement to inform sport organisations, research scientists, policymakers, conference organisers, safeguarding officers, sport medicine clinicians and survivors themselves.

\section{INTRODUCTION}

By means of my story, I am striving towards structural changes to achieve a safe environment in sports without abusive behaviour, sexual abuse, and intimidation. Together with Rachael (Denhollander) and Sheldon (Kennedy), I would like to take a stance to raise the subject globally. (Renald Majoor)

Sport, as a microcosm of society, is not immune to the abuse of its stakeholders. Attention to abuse in sport has recently become a priority following several high-profile cases of athlete abuse from around the world. In 1996, the game of ice hockey in Canada was stunned by the allegations of sexual abuse of the former National Hockey League star, Sheldon Kennedy by his junior coach, Graham James. ${ }^{1}$ The allegations of sexual abuse in English football by Andy Woodward in $2016^{2}$ led to disclosures in football by other players outside of the
UK such as Majoor who revealed his experience in 2017 in the Netherlands. ${ }^{3}$ Denhollander, the first woman to publicly accuse the team doctor of USA Gymnastics (Dr Larry Nassar) of sexual abuse, was instrumental in leading an army of survivors to give testimony at his criminal trial in 2018 which rocked the institutional foundations of the sport of gymnastics and the US Olympic Committee. ${ }^{4} \mathrm{~A}$ 2020 human rights report revealed the shocking revelation of widespread abuse in Japanese developmental sport. ${ }^{5}$ Allegations of sexual abuse of many female players from the African basketball team from Mali were reported in the New York Times in 2021. ${ }^{6}$ These high-profile cases not only illuminated the dark underbelly of sport, but also sparked conversation, raised awareness and incited changes in policies with the intention of better protecting athletes from suffering similar atrocities.

In a seminal consensus statement on harassment and abuse in sport, the International Olympic Committee (IOC) describes four types of harassment and abuse: psychological, physical, sexual and neglect, and asserts that all athletes have a right to engage in 'safe sport'. 7 The consensus statement also proposes the mechanisms by which harassment and abuse are expressed in the sporting context (ie, non-contact, contact, hazing, cyber, negligence), as well as the potential impacts of harassment and abuse on athletes and sport organisations. Principles for the prevention of harassment and abuse in sport are discussed, and recommendations are posited targeting athletes, sport organisations, sport medicine and sport science researchers. ${ }^{7}$ The obligation to protect athletes from harassment and abuse is embedded in the statutory governing documents of sport, including the Olympic Charter ${ }^{8}$ and the IOC Code of Ethics. ${ }^{9}$ The IOC also produced a knowledge translation document in the form of a Safeguarding Toolkit to assist the development of safeguarding practices in International Sport Federations and National Olympic Committees. ${ }^{10}$

Many sports organisations have been active in the field of athlete safeguarding. One mechanism adopted by sport organisations is the engagement of survivors of abuse in sport: typically, as guest speakers at conferences ${ }^{11}$ or sport-related educational initiatives. $^{12}$ Unfortunately, many sport organisations do not have the trauma-informed expertise to engage survivors safely and effectively; and in doing so, may unintentionally retraumatise survivors if erroneous methods of engagement are employed. For some survivors, this experience may 
compound the original trauma, and likewise it represents an area of vulnerability for the organising entity. ${ }^{13}$

This project is realised through the collaboration between survivors of sexual abuse in sport and experts in the field of safeguarding in sport with both clinical and research experience (MM-sport medicine clinician scientist with expertise in safeguarding policy development and implementation in sport organisations; TV-researcher in forensic psychology). A trauma-informed approach to the collaboration was implemented. While survivors may play any role in sport organisations, we will focus on the engagement of survivors in safeguarding initiatives. The principles outlined in this paper stem from lessons learnt from survivors' positive and negative experiences in safeguarding collaborations, in addition to an exploration of the related scientific literature from both inside and outside of sport. The purpose of this paper is to explore the rationale (the 'why') for partnering with survivors of harassment and abuse in sport in safeguarding initiatives. We also introduce a living 'Conceptual Framework for Survivor Engagement' to guide the safe and effective collaboration with survivors (the 'how'). The conceptual framework is designed to inform sport organisations, research scientists, policy-makers, conference organisers, safeguarding officers, sport medicine clinicians and survivors themselves. Finally, we explore the role of the sport medicine clinician in collaborations with survivors.

\section{SCIENTIFIC BACKGROUND}

A search of the scientific literature, including PubMed, Medline, Sport Discus, Embase, Google Scholar, Web of Science and Scopus, was completed using the keyword phrases: 'patient and public involvement', 'narratives', 'personal stories', 'expert by experience', 'patient experience', 'user involvement', 'patient involvement', 'lived experience', 'consumer participation', 'co-production' and 'experience-based co-design'. Combining these keyword phrases or MeSH headings with 'sport', or 'athlete' resulted in zero results, thus the science review focuses on the non-sport literature. A search of the grey literature in the field was conducted using the keywords of 'athlete voice', 'harassment and abuse' and 'sport', which revealed two relevant resources. $^{14} 15$

\section{Terminology}

The term 'survivor' first emerged in the sexual violence sector as a positive expression that was seen to be more empowering, and signified control and mastery rather than passivity embodied in the term 'victim'. ${ }^{16}$ Other terms used in the literature to describe individuals who have experienced a traumatic event are 'expert by experience', or 'lived experience', and initiatives completed through collaboration with individuals who experienced a traumatic event is known as 'coproduction'. In 2007, Hunter and Richie $^{17}$ defined co-production as 'a particular approach to partnership between people who rely on services and the people and agencies providing those services' underscoring the philosophy of equitable partnerships between professionals and the end user. Coproduction is used commonly in the National Health Service of the $\mathrm{UK}^{18}$ and is described by the WHO to imply that the individual adds value beyond the role of a passive supplier of opinion to a more active role of facilitating change. ${ }^{19}$ There is also a managerial logic in which coproduction is seen to add value to a project in a cost-effective manner. ${ }^{20}$ Different theoretical constructs that can be applied to these terms include the rights-based argument that identifies the right of individuals to participate in decisions that directly affect them. ${ }^{17}$ The

\section{Glossary}

Harassment and abuse in sport non-accidental violence occurring during sport participation that is rooted in discriminations and may result in negative impacts for athletes and

sport organisations. There are four types of harassment and abuse in sport: psychological, physical, sexual and neglect. ${ }^{9}$

Safe sport an athletic environment that is respectful, equitable and free from all forms of non-accidental violence to athletes. ${ }^{9}$

Safeguarding the action that is taken to promote the welfare of an athlete and protect them from harm. ${ }^{50}$

\section{Survivor}

A label self-ascribed by someone having experienced a traumatic experience that connotes the individual as having agency and initiative; a focus on active resistance and recovery with a rejection of ascribed passivity while highlighting a person's strengths to support their ability to cope with a traumatic experience, enabling them to change and carry on with their live. $^{18}$

\section{Grooming}

A term used to describe the process by which sex offenders carefully initiate and maintain sexually abusive relationships with children. Grooming is a conscious, deliberate and carefully orchestrated approach used by the offender. The goal of grooming is to permit a sexual encounter and keep it a secret. ${ }^{51}$

Trauma-informed care is an approach in the human service field that understands and considers the pervasive nature of trauma and promotes environments of healing and recovery, rather than practices and services that may inadvertently retraumatise. It recognises the presence of trauma symptoms and acknowledges the role trauma may play in an individual's life-including service staff. Trauma informed care emphasises understanding, respecting and appropriately responding to the effects of trauma at all levels. ${ }^{4452}$ At the organisational level, trauma-informed care incorporates a cultural change to incorporate the following six principles:

- Addressing potential retraumatizing policies and procedures.

- Conducting early and respectful trauma screening and assessment for all.

- Establishing an internal trauma team.

- Ensuring administrative commitment to integrating a traumainformed culture.

- Providing introductory training to all relevant staff.

- Including survivors in the planning and evaluation of services. $^{15}$

experience-based argument values the experiences of individuals in shaping knowledge, research direction and improvements in service. ${ }^{17}$ For the purposes of this paper, we use the term 'survivor', which is more commonly used, while recognising that individuals may define their personal experience(s) using their own language.

\section{Scientific literature reviewing survivor collaborations from outside of sport}

The successful engagement and collaboration of survivors has been published in a variety of settings outside of sport, most prominently in the delivery of mental healthcare ${ }^{21}$ and in mental health research, both of which demonstrate the positive benefits for survivors of mental health illnesses (including those who are living with mental illness) as well as the organising institution. ${ }^{223}$ 
Survivors of mental illness have also been successfully involved in teaching mental health competencies to nursing students. ${ }^{24}$ Cancer research is another domain that has published benefits of cancer survivor engagement. ${ }^{25}$ Other examples of mutually beneficial survivor engagement in policy development, advocacy work, project design and implementation are published in the literature on violence against women, ${ }^{26}$ human trafficking, ${ }^{27}$ domestic violence, ${ }^{28}$ disability and social work, ${ }^{29}$ child abuse ${ }^{30}$ and human torture. ${ }^{31}$

\section{Scientific literature reviewing collaborations with survivors of abuse from inside sport}

There is a paucity of publications involving survivors of abuse in sport. It is only recently that survivors have been active partners in project design, implementation and delivery of research on abuse in sport, beyond the tokenism of being involved only as respondents to surveys, or participants in interviews. ${ }^{32}$ An educational project engaging survivors is the 2015 project cofunded by the Erasmus + Programme of the European Union, seven universities, four sports federations and a child protection charity. Survivors were engaged in this project as research participants, active agents in delivering acknowledgement forums and developers of educational materials. ${ }^{33}$ While many sport organisations have engaged survivors in safeguarding efforts, a few safeguarding programmes exist that are survivor-led (ie, De Stilte Verbroken (Broken Silence Foundation) (survivor support), ${ }^{34}$ The Army of Survivors (advocacy), ${ }^{35}$ Respect in Sport (education) ${ }^{36}$ ).

\section{WHY ENGAGE SURVIVORS OF ABUSE IN SPORT IN SAFEGUARDING?}

Although there are no publications delineating the benefits of engaging survivors in safeguarding in sport, there is evidence from outside of sport of benefits for both the survivor and the organisation.

\section{Benefits for the survivor}

A study by Cooke $e t a l^{37}$ evaluated the impact on survivors of personality disorders delivering training to medical professionals. Not only did the survivors report an improvement in their selfesteem, but they also felt that the experience was beneficial for their recovery, as past challenging experiences were reframed to take on new meaning. ${ }^{37}$ Another study of youth survivors of mental health illness delivering mental health support programming showed that the survivors reported feeling valued and that the experience facilitated the reclaiming of agency and control. ${ }^{38}$ In addition, the experience enabled the survivors to reorganise their identity structure as a 'professional'. ${ }^{36}$ This process of identity reconstruction ${ }^{39}$ is supported by a study by Jones and Pietilä ${ }^{40}$ that evaluated the transformation process of becoming an 'expert by experience'. They demonstrated that the experience helped the survivors to recontextualise their past experience and to construct a new identity, (ie, as a professional or political activist). ${ }^{40}$ Thus, the past challenging experiences became both a source of knowledge expertise, and a motivator for advocating for change.

Survivors do not wish to be heard simply to be heard. They wish to be heard because they desire to spark change - to know that their suffering matters enough to produce action. When a survivor can help ensure that others do not suffer as they have, it helps give meaning to what has been endured, thereby repurposing the trauma. Whether the survivor's experience will be healing, or retraumatizing, is dependent on what the organization is truly willing to do with the message it receives. (Rachael Denhollander)

\section{Benefits for the organization}

In the bioscience's technology domain, public engagement in biotech developments has resulted in both an increase in stakeholder trust in the organisation, as well as more relevant outcomes. ${ }^{20}$ From the mental health sector, institutional benefits of engaging with individuals with lived experience include a more equitable workplace, enhanced staff development, improved community engagement and reduced expenditures. ${ }^{41}$ While there are no publications outlining the benefits for partnering with survivors in safeguarding initiatives, there are many potential benefits for sport organisations that can be realised. Initially, survivor testimonies are required as evidence to support investigations of allegations of abuse. In addition, survivors are the best equipped to alert organisations to the vulnerabilities in the safeguarding systems, thus allowing the organisation to adapt in response to identified deficits. For example, survivors can provide insight into the grooming processes, relationship dynamics (when someone has power over another), secrecy and culture around abusive relationships. Finally, survivors' experience with disclosure can provide helpful feedback for quality improvement of reporting mechanisms.

\section{WHAT ARE THE POTENTIAL ROLES FOR SURVIVORS OF ABUSE IN SAFEGUARDING IN SPORT?}

...it's about doing my part, which is keeping the issue of abuse in the

forefront long enough for change to happen. (Sheldon Kennedy)

Survivors can be involved in many aspects of safeguarding in sport. To determine the role for the survivor, the survivor's interests, skill set, knowledge and stage of recovery should be considered. ${ }^{42}$ In addition, the sport organisation should evaluate their institutional needs, to ascertain the gaps requiring survivor involvement. Depending on the analysis of both survivor and institutional factors, there is a broad range of potential roles for survivors in all aspects of safeguarding. A survivor may be involved in more than one role either over time, or concurrently depending on the survivor interests, availability, skill set and institutional need. The collaborative relationship could be either generated by invitation from a sport organisation or from a survivor, or group of survivors (see figure 1).

\section{HOW TO COLLABORATE EFFECTIVELY AND SAFELY WITH SURVIVORS OF ABUSE IN SPORT}

While there are many benefits from collaborating with survivors in safeguarding initiatives, it is important to acknowledge that there may be risks if the survivor engagement is poorly executed. A potential outcome of a poorly executed survivor engagement may be that the survivor perceives the collaboration as being only symbolic, whereby they were engaged not on the basis of merit, but merely as an act of tokenism. ${ }^{23}$

Sometimes I feel like I have been put on a pedestal and being used by the organization to look like they care. (Sheldon Kennedy)

Another potential outcome of a poorly executed survivor engagement is the retraumatisation of the survivor if the organising body unintentionally fails to recognise, and to plan mitigation strategies and/or support for the trauma-related vulnerabilities of the survivor. ${ }^{33}$

Given these potential risks, what should a sport organisation do to prevent causing further harm to a survivor? Mayer and McKenzie, ${ }^{38}$ in their study of coproduction with survivors of youth mental illness, reported that the survivors valued 'control', 'respect' and 'feeling valued' the most. They attributed this to the organisational approach which emphasised equality of the 


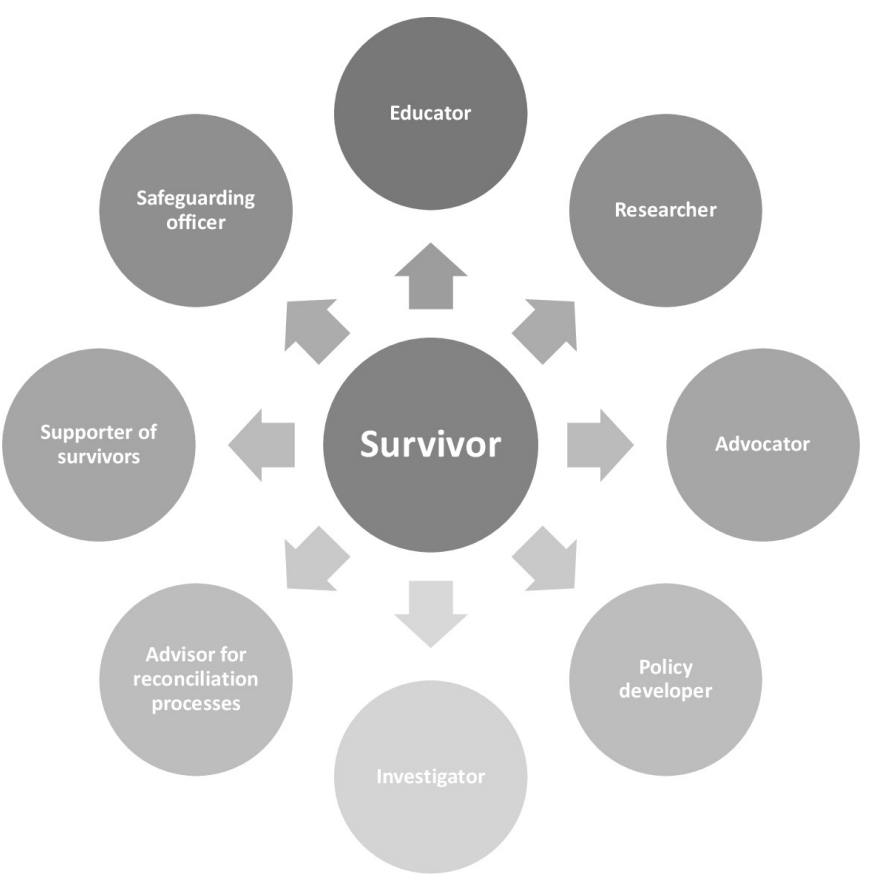

Figure 1 Potential roles for survivors of abuse in sport in safeguarding initiatives (survivors may be engaged in one or more roles over time, or concurrently).

survivor with the experts by qualification, empowerment and agency.

Yes definitely, in the Netherlands they think the world of me: I gained much respect from people and organisations and many people thanked me for what I do because they also realise that this work is really necessary. (Renald Majoor)

An example of an effective survivor engagement in conducting research should involve survivors in all aspects of the project including topic selection, project design, funding control, and involvement in data collection, interpretation and results dissemination. ${ }^{43}$ Sadiq-Tang ${ }^{31}$ attributes the success of a survivor-led advocacy group on human torture to the overarching principle of 'working with' and not 'working for' survivors.

\section{A conceptual framework for engagement of survivors of abuse in sport}

To realise successful survivor collaboration, the authors drew on their experience from research, clinical practice, knowledge translation and survivor lived experience in the field to produce a conceptual framework. This framework is designed as a living document, with the intention of future iterations as the framework is implemented and experience is gained. There are general principles that should be implemented throughout the entire process, as well as best practice principles that are unique to the various phases of survivor engagement: (1) the pre-engagement, (2) the invitation, (3) the collaboration and (4) the follow-up. For details see figure 2 .

\section{General principles}

Effective survivor engagement requires a solid foundational 'believed, acknowledged, safe and empowered (BASE)' of general principles, which includes the implementation of tangible actions to provide survivors with objective evidence which engenders a feeling of being BASE. For example, there should be intentional organisational commitment to the collaboration with an acknowledgement of the importance of survivor-centred actions. The organisation should ensure that comprehensive safeguarding policies and procedures that are human rights compliant, publicised, implemented, monitored and evaluated. The organisation should also ensure that their organisation is a 'safe space' by creating a culture shift to one of transparency where human rights are upheld in addition to implementing processes for the reporting of harassment and abuse. ${ }^{44}$ Recognising the broad spectrum of harassment and abuse experiences, and the varied impacts on athletes, it is important to acknowledge that survivors may have had traumatic experiences with potential ongoing vulnerabilities and difficult present circumstances. Thus, the organisation should ensure that all individuals interacting with survivors (policy-makers, project managers, researchers, coaches, sport officials, lawyers etc) receive trauma-informed training, which encompasses the 4R principles outlined by Hopper et $a l^{45}$ : 1. Realising the widespread impact of trauma (trauma awareness).

2. Recognising the signs and symptoms of trauma.

3. Responding by fully integrating knowledge about trauma into policies, procedures and practices.

4. Avoiding Retraumatisation by using sensitive language and actions.

Survivor trust will be further enhanced through the provision of appropriate confidentiality policies, as well as evidence of the prioritisation of survivors' rights and needs. The operationalisation of this foundational work can pose challenges for the organising institution requiring the planning of mitigation strategies: (1) the need for time to build survivor trust, (2) the need for trauma-informed competence and (3) the need for financial and human resources. Support from the organisation's leadership is essential for the success of safeguarding programmes. ${ }^{46}$

Policies don't change culture - they can collect dust on the shelf; however, when athlete welfare becomes a leadership priority; you see and feel the action as a survivor. (Sheldon Kennedy)

\section{The pre-engagement phase}

The pre-engagement phase occurs prior to inviting a survivor to collaborate on a safeguarding project. During the preengagement phase, it is important to build a trusting relationship with the survivor, and to learn of their motivations for participating (see table 1). Survivor motivation to participate is individual, often multifactorial and can change over time. It is also essential to understand the survivor's skill set, needs and current stage of recovery: (1) safety; (2) remembrance, integration and mourning and (3) reconnecting with others. ${ }^{47}$ The time spent in the pre-engagement phase will inform the sport organisation of the survivor's interests and abilities to partner in various safeguarding initiatives and manage expectations for both the survivor and the sport organisation.

\section{The survivor invitation phase}

Building on the pre-engagement phase, the invitation to participate in a project or event should provide the survivor with a clear understanding of the task, commitment, expected outcomes, available support and timelines, thereby ensuring informed consent. The invitation process should be a two-way dialogue of sharing of ideas. If the event involves public speaking, the invitation should include a clear description of the room, rules around filming and photographs, attendance of the press, duration, list of participants and available supports. ${ }^{48}$ 


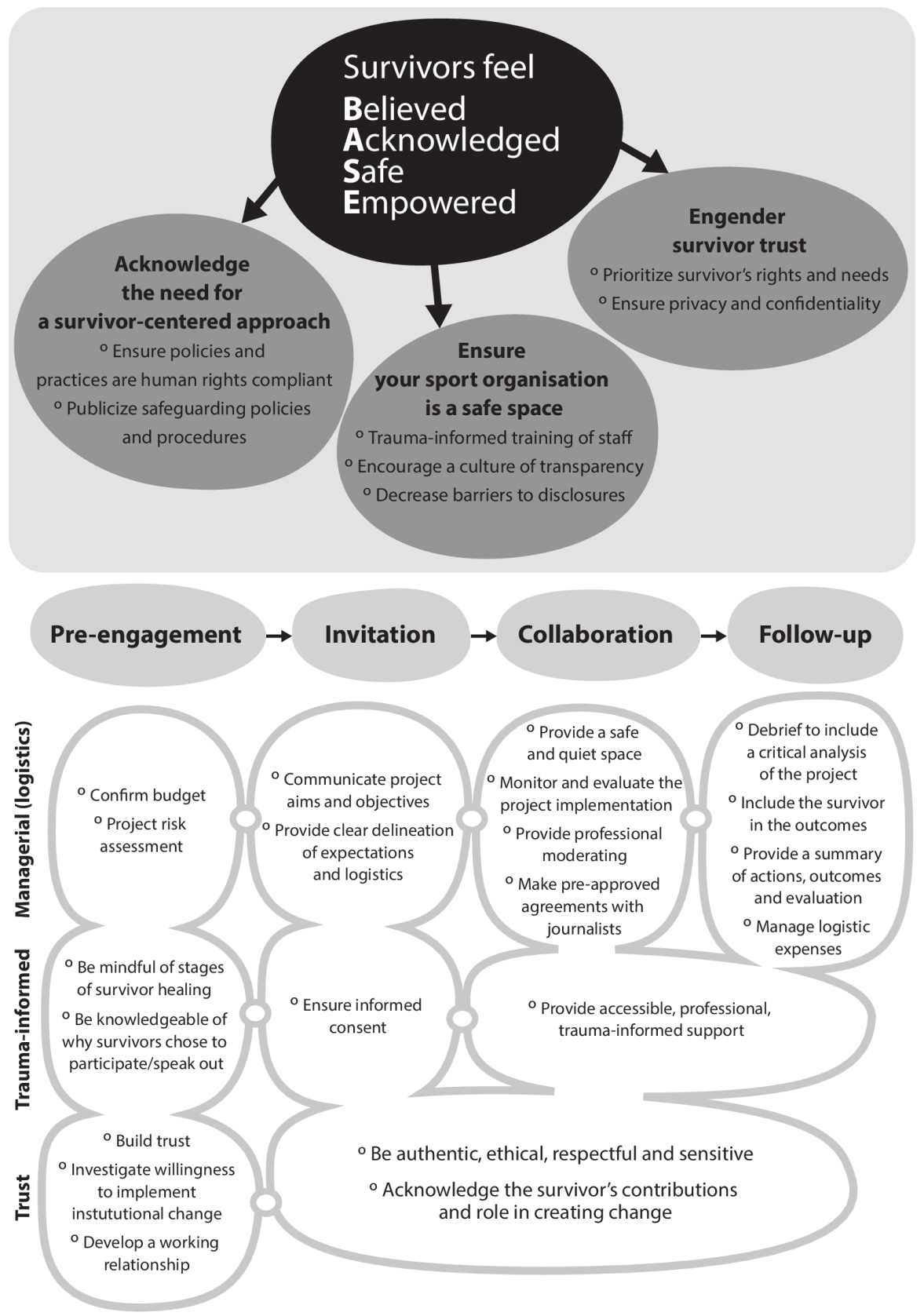

Figure 2 A conceptual framework for engagement of survivors of abuse in sport: a conceptual framework for the safe and effective engagement of survivors of abuse in sport in safeguarding initiatives. The top half of the framework in the grey box demonstrates the general principles of survivor engagement that should be applied during all phases of the survivor engagement. The bottom half of the figure illustrates strategies to be applied during the 4 phases of survivor engagement: (1) pre-engagement, (2) invitation, (3) collaboration and (4) follow-up ${ }^{53}$.

It is important to me that I feel at ease when I tell my story. I regularly practise beforehand and I like to be accompanied by my trust person. (Renald Majoor)

Working with the survivor: the collaboration phase

During the orientation of the survivor, it is important to emphasise that the project/event is not intended to be therapeutic, and thus external, accessible and trauma-informed support should be provided as needed. The project/event should be structured to empower the survivor in a culture of safety and respect. Survivorapproved agreements with the media should be processed prior to the event/realisation of the project to ensure clear understanding of boundaries and safety for the survivor.
A trauma-informed approach will provide the survivor with options based on their comfort level. Many survivors are hesitant to express preferences that help them feel safer, thus asking trauma-informed questions to help elicit the best scenarios for survivors can help empower them to voice their needs. (Rachael Denhollander)

The follow-up phase

An important component of the follow-up phase of the engagement is the provision of trauma-informed support for the survivor, such as referral to an experienced mental health worker or support group as needed. A debriefing with both the survivor(s) and project staff provides the opportunity for critical analysis to inform future project planning. A final report 
Table 1 Potential motivations for survivor participation and potential reasons for lack of participation in safeguarding initiatives

\begin{tabular}{|c|c|}
\hline $\begin{array}{l}\text { Potential motivations for survivor } \\
\text { participation }\end{array}$ & $\begin{array}{l}\text { Potential reasons for lack of survivor } \\
\text { participation }\end{array}$ \\
\hline To prevent future abuse & $\begin{array}{l}\text { Fear of consequences, most often related to } \\
\text { sport participation }\end{array}$ \\
\hline To stop the abuse & Fear of not being believed or taken seriously \\
\hline To educate others & Shame/guilt \\
\hline To raise awareness & $\begin{array}{l}\text { Inadequate and/or ineffective institutional } \\
\text { safeguarding policies }\end{array}$ \\
\hline To advocate for change & Fear of losing support (ie, coaching, financial) \\
\hline To disclose the abuse & $\begin{array}{l}\text { Fear of being responsible for perpetrators } \\
\text { outcome }\end{array}$ \\
\hline $\begin{array}{l}\text { To give voice to other survivors } \\
\text { through sharing their personal story }\end{array}$ & Inability to articulate the trauma \\
\hline $\begin{array}{l}\text { To support and inform scientific } \\
\text { research }\end{array}$ & $\begin{array}{l}\text { Inability to recognise/ realise their experience } \\
\text { as abuse }\end{array}$ \\
\hline $\begin{array}{l}\text { To underscore the need for } \\
\text { safeguarding }\end{array}$ & Fear of harming loved ones \\
\hline $\begin{array}{l}\text { To seek revenge, punishment, } \\
\text { retribution, financial gain }\end{array}$ & Fear of disappointing loved ones \\
\hline To start mediation/judicial process & Threats \\
\hline
\end{tabular}

evaluation should be circulated including the outcomes, future plans, acknowledgement of the survivor's role and incorporating the feedback of the postevent ${ }^{48}$ (see table 2).

Survivors do not desire to relive the trauma of their abuse simply for the sake of reliving it, as if the act of retelling the story itself is therapeutic. On the contrary, there is significant personal cost in continuing to be known by one's abuse. Thus, it is critical that institutions understand before engaging a survivor, that engagement with no intent to implement steps based on the survivor's participation, signals paternalistic tokenism - a feeling of having "done a good deed" by listening to a "wounded person" Thus, an organization must be prepared to effect change based on what the survivor shares. (Rachael Denhollander)

\section{THE ROLE OF THE SPORT MEDICINE PHYSICIAN}

Sport medicine physicians have an important role to play in working with survivors of abuse and harassment in sport. As proposed by Marks et al, ${ }^{49}$ sport medicine clinicians, through trauma-informed training, should develop the clinical competence to recognise the signs and symptoms of harassment and abuse, to manage and report disclosures of harassment and abuse, and to provide an interdisciplinary comprehensive management plan for the survivor, as well as affected families, teammates

Table 2 Recommendations for successful survivor engagement, and actions to avoid during collaborations with survivors

\begin{tabular}{|c|c|}
\hline Recommendations & Actions to avoid \\
\hline $\begin{array}{l}\text { Prioritisation of athlete safeguarding by } \\
\text { sport leadership }\end{array}$ & Tokenism \\
\hline Survivor-centred approach & $\begin{array}{l}\text { Making decisions for survivors: telling the } \\
\text { survivor what they can or cannot do }\end{array}$ \\
\hline Implement trauma-informed training & Retraumatisation \\
\hline Provide respectful and ethical support & Paternalistic communication \\
\hline $\begin{array}{l}\text { Follow-up on commitments and project } \\
\text { outcomes }\end{array}$ & Inaction on commitments \\
\hline $\begin{array}{l}\text { Ensure safe institutional policies and } \\
\text { procedures }\end{array}$ & $\begin{array}{l}\text { Overprotection: excessive shielding or } \\
\text { restricting the survivor's behaviour }\end{array}$ \\
\hline Engender survivor trust & Requests for testimony only \\
\hline
\end{tabular}

and entourage. In addition to the therapeutic relationship that sport medicine clinicians may have in supporting survivor recovery, sport medicine physicians can play an important role in informing the development of institutional policies and procedures around survivor engagement, and in educating organisational personnel in trauma-informed principles and practices. Throughout the entire engagement process, the sport medicine physician may be called on for clinical support of the survivor as needed. In addition, sport medicine physicians play a role in supporting research on safeguarding. ${ }^{46}$

\section{CONCLUSION}

A survivor-centred approach is required for the successful engagement of survivors in sport safeguarding initiatives. There are many benefits for both the survivor and the sport organisation to be realised from the collaboration. To avoid retraumatisation, tokenism and other harms, sport organisations should equip all personnel interacting with survivors with appropriate trauma-informed skills and should ensure that their policies and procedures facilitate safe and effective partnerships with survivors of abuse in sport. A conceptual framework for the safe and effective engagement of survivors in safeguarding initiatives is introduced to provide sport with a bespoke guide to facilitate the survivor engagement process. The value-added contributions of survivors of harassment and abuse in sport in safeguarding initiatives can play an important role in realising the objective of a safe sport environment for all athletes.

So much work remains; so much evil to fight; so much healing to reach for; so many wounded to love. Consider this your invitation to join in that work. To do what is right, no matter the cost... (Rachael Denhollander)

Twitter Margo Mountjoy @margo.mountjoy and Tine Vertommen @TineVertommen

Acknowledgements The authors would like to thank and acknowledge all survivors that have come forward to protect others in sport.

What is already known

Harassment and abuse occur in sport.

- Some survivors of harassment and abuse in sport are engaged in survivor-led safeguarding activities.

- There are no guidelines in the sport literature outlining how to safely engage survivors of harassment and abuse from sport in safeguarding-related efforts.

- The non-sport literature demonstrates benefits of engaging survivors for both the survivor as well as for the organisation.

What are the new findings

There are many potential roles for survivors of harassment and abuse from sport in safeguarding.

- A trauma-informed approach to the four stages of engagement, (1) pre-engagement, (2) the invitation, (3) collaboration and (4) follow-up, should be employed to reduce the risk of triggering retraumatisation.

- A survivor-centred approach to engaging survivors of harassment and abuse from sport is one where the survivor feels believed, acknowledged, safe and empowered.

- Sport medicine clinicians have an important role to play in supporting survivors in safeguarding initiatives. 
Contributors MM: lead author and responsible for concept creation, project coordination and drafting; approval of final draft. TV: responsible for concept creation, drafting; approval of final draft. RD, SK and RM: responsible for experiential content, drafting of text and approval of content, tone and resonance; approval of final draft.

Funding The authors have not declared a specific grant for this research from any funding agency in the public, commercial or not-for-profit sectors.

Competing interests None declared.

Patient consent for publication Consent obtained directly from patient(s)

Ethics approval This study does not involve human participants.

Provenance and peer review Not commissioned; externally peer reviewed.

ORCID iD

Margo Mountjoy http://orcid.org/0000-0001-8604-2014

\section{REFERENCES}

1 Wikipedia. Sheldon Kennedy, 2020. Available: https://en.wikipedia.org/wiki/Sheldon_ Kennedy [Accessed 1 Jan 2021].

2 Woodward A. Former footballer Andy Woodward tells of sexual abuse. BBC news, 2016. Available: https://www.bbc.com/news/uk-england-38007412 [Accessed 1 Jan 2021].

3 Majoor R. Reason and initiator: Renald Majoor de Stilte Verbroken, 2021. Available: https://destilteverbroken.nl/ [Accessed 1 Jan 2021].

4 Denhollander R. About Rachael Denhollander, 2020. Available: https:// rachaeldenhollander.com/ [Accessed 1 Jan 2021].

5 Watch HR. "I was hit so many times, I can't count." Abuse of child athletes in Japan, 2020. Available: https://www.hrw.org/report/2020/07/20/i-was-hit-so-many-times-icant-count/abuse-child-athletes-japan [Accessed 1 Nov 2021].

6 New York Times. World basketball chief steps aside amid sexual abuse investigation, 2021. Available: https://www.nytimes.com/2021/06/13/sports/olympics/fibabasketball-mali-sexual-abuse.html?action=click\&module=RelatedLinks\&pgtype= Article [Accessed 7 Dec 2021].

7 Mountjoy M, Brackenridge C, Arrington M, et al. International Olympic Committee consensus statement: harassment and abuse (non-accidental violence) in sport. $\mathrm{Br}$ J Sports Med 2016;50:1019-29.

8 International Olympic Committee. Olympic Charter-In force as from 17 July 2020, 2020. Available: https://www.olympic.org/documents/olympic-charter [Accessed 1 Jan 2021].

9 International Olympic Committee. IOC code of ethics, 2020. Available: https://www. olympic.org/code-of-ethics [Accessed 1 Jan 2021].

10 International Olympic Committee. Safeguarding athletes from harassment and abuse in sport: IOC toolkit for IFs and NOCs, 2019. Available: https://library.olympics.com/Default/doc/ SYRACUSE/171450/safeguarding-athletes-from-harassment-and-abuse-in-sport-ioc-toolkitfor-ifs-and-nocs-related-to-cre?_Ig=en-GB [Accessed 8 Sept 2021].

11 Safe Sport International Conference, 2020. Available: https://www.sportanddev.org/ en/event/safe-sport-international-conference-0 [Accessed 1 Nov 2021].

12 Mountjoy M, Vertommen T, Burrows K, et al. \#SafeSport: safeguarding initiatives at the Youth Olympic Games 2018. Br J Sports Med 2020;54:176-82.

13 Harris M, Fallot R, eds. Using trauma theory to design service systems. New directions for mental health services. San Francisco: Jossey-Bass, 2001.

14 International Olympic Committee Athlete 365. Hearing and respecting the athlete's voice. Hearing and respecting the athletes' voice - Athlete365 (olympics.com). Available: https://olympics.com/athlete365/integrity/hearing-and-respecting-theathletes-voice/ [Accessed 1 Nov 2021].

15 Voices for truth and dignity: combatting sexual violence in European sport through the voices of those affected. Available: http://voicesfortruthanddignity.eu/ [Accessed 1 Nov 2021].

16 Papendick M, Bohner G. "Passive victim - strong survivor"? Perceived meaning of labels applied to women who were raped. PLoS One 2017;12:e0177550.

17 Hunter S, Ritchie P. Introduction: With, not to: Models of co-production in social welfare. In: Hunter S, Ritchie P, eds. Co-Production and personalisation in social care: changing relationships in the provision of social care. London: Jessica Kingsley Publishers, 2007.

18 Filipe A, Renedo A, Marston C. The co-production of what? knowledge, values, and social relations in health care. PLoS Biol 2017;15:e2001403.

19 Kickbusch I, Gleicher D. Governance for Health in the 21st Century. Copenhagen: World Health Organization (WHO) Regional Office for Europe, 2012.

20 Marris C, Rose N. Open engagement: exploring public participation in the biosciences. PLOS Biol 2010;8:e1000549.

21 Neech SGB, Scott H, Priest HM, et al. Experiences of user involvement in mental health settings: user motivations and benefits. J Psychiatr Ment Health Nurs 2018:25:327-37.

22 Tapsell A, Martin KM, Moxham L, et al. Expert by experience involvement in mental health research: developing a wellbeing brochure for people with lived experiences of mental illness. Issues Ment Health Nurs 2020;41:194-200.
23 Ennis L, Wykes T. Impact of patient involvement in mental health research: longitudinal study. Br J Psychiatry 2013;203:381-6.

24 Horgan A, Manning F, Bocking J. To be treated as a human: using co-production to explore experts by experience involvement in mental health nursing education - the commune project. Int J Mental Health Nursing 2018.

25 Klein S, Tracy D, Kitchener HC, et al. The effects of the participation of patients with cancer in teaching communication skills to medical undergraduates: a randomised study with follow-up after 2 years. Eur I Cancer 1999:35:1448-56.

26 Gilfus M, Fineran S, Cohan D. Research on violence against women: creating survivorinformed collaborations. Violence Against Women 1999;5:1194-212.

27 Lockyer S. Beyond inclusion: survivor-leader voice in anti-human trafficking organizations. J Human Trafficking 2020. doi:10.1080/23322705.2020.1756122

28 Hague G. Domestic violence survivors' forums in the UK: experiments in involving abused women in domestic violence services and policy-making. I Gender Studies 2006:191-203.

29 MacDermott D, Harkin-MacDermott C. Co-producing a shared stories narrative model for social work education with experts by experience. Practice 2020;32:89-108.

30 New South Wales Officer of the Children's Guardian. Engaging sensitively with survivors of abuse. Available: https://www.ocg.nsw.gov.au/ArticleDocuments/802/ Engaging_sensitively_with_survivors.pdf.aspx?Embed=Y [Accessed 8 Sept 2021].

31 Sadiq-Tang S. Building survivor activism: an organisational view. Torture Journal 2018:28:140-9.

32 Harris C, Hartill M. Sexual abuse 'survivor' research in sport. In: Lang M, ed. The Routledge Handbook of athlete welfare. New York, NY: Routledge, 2012: 277-89.

33 Rulofs B, Doupona-Topic M, Diketmüller R. Final report: voices for truth and dignitycombatting sexual violence in European sport through the voices of those affected. Cologne: German Sport University, 2020.

34 Verbroke DS. Broken silence Foundation). Available: https://destilteverbroken.nl/ [Accessed 8 Sept 2021].

35 The army of survivors. Available: https://www.thearmyofsurvivors.org/ [Accessed 8 Sept 2021].

36 Respect in sport. Available: https://www.respectgroupinc.com/respect-in-sport/ [Accessed 8 Sep 2021].

37 Cooke S, Daiches A, Hickey E. Narratives of experts by experience: the impact of delivering training in partnership on the subject of personality disorder. $J$ of Mental Health Training, Education Practice 2015;10:234-44.

38 Mayer C, McKenzie K. '... it shows that there's no limits': the psychological impact of co-production for experts by experience working in youth mental health. Health Soc Care Community 2017:25:1181-9.

39 Breakwell GM. Woman: group and identity? Womens Stud Int Q 1979;2:9-17.

40 Jones M, Pietilä I. Personal perspectives on patient and public involvement stories about becoming and being an expert by experience. Sociol Health IIIn 2020;42:809-24.

41 Suicide Prevention Resource Centre. Benefits for organizations when they incorporate lived experience. Available: https://www.sprc.org/livedexperiencetoolkit/about [Accessed 8 Sep 2021].

42 University at Buffalo Center for Social Research. What is trauma-informed care? what is Trauma-Informed care? Available: http://socialwork.buffalo.edu/social-research/ institutes-centers/institute-on-trauma-and-trauma-informed-care/what-is-traumainformed-care.html [Accessed 8 Sep 2021].

43 Nicholls V, Wright S, Waters R. Surviving user- led research: reflections on supporting user-led research projects. London: Mental Health Foundation, 2003.

44 Brackenridge C, Fasting K, Kirby S. Protecting children from violence in sport: a review with a focus on industrialized countries. UNICEF Innocenti Research Centre, 2010. ISBN: 978-88-89129-96-8. www.unicef-irc.org/publications

45 Hopper E, Bassuk E, Olivet J. Shelter from the storm: trauma-informed care in homelessness services settings. Open Health Services and Policy J 2010;3:80-100.

46 Parent S, Demers $\mathrm{G}$. Sexual abuse in sport: a model to prevent and protect athletes. Child Abuse Rev. 2011:20:120-33.

47 Herman J. Trauma and recovery. New York, NY: Basic Books, 1992.

48 Hartill M, Murphy K, Taylor S. Good practice guide: supporting individuals affected by sexual violence in sport-a guide for sport organisations. Cologne: German Sport University, 2020.

49 Marks S, Mountjoy M, Marcus M. Sexual harassment and abuse in sport: The team physician's role in prevention. Br J Sports Med 2012;46:905-8.

50 National Society for the Protection of Cruelty to Children. Safeguarding children and child protection, 2020. Available: https://learning.nspcc.org.uk/safeguarding-childprotection [Accessed 1 Jan 2021].

51 Knoll J. Teacher sexual misconduct: grooming patterns and female offenders. J Child Sex Abus 2010;19:371-86.

52 Byrne L. Promoting lived experience perspective. Discussion paper prepared for the Queensland Mental Health Commission, 2017. Available: https://www.researchgate net/publication/313757552 [Accessed 8 Sep 2021].

53 Wilson C, Pence D, Conradi L. In encyclopedia of social work. National association of social workers press and Oxford university press, 2013. Available: https://doi.org/10. 1093/acrefore/9780199975839.013.1063 [Accessed 8 Sep 2021]. 